\title{
Exploring how to build innovation and entrepreneurship education ecosystems in universities in Guangdong against the backdrop of the Guangdong-Hong Kong-Macau Greater Bay Area
}

\author{
Qianyu Zhu \\ Guangdong University of Foreign Studies, Guangzhou, Guangdong 510420
}

\begin{abstract}
Universities are cradles for intellectual and technical innovators, and thus building an innovation and entrepreneurship education ecosystem in universities is of strategic importance for national development. Most studies in China, from the perspective of collaborative innovation, used the EPM model to analyze the features, elements and operational modes of innovation and entrepreneurship education ecosystems in universities based on theories of symbiosis, competition and cooperation, coordination, networking, and the exchange mechanism. Boosted by the strategies to develop the Guangdong-Hong Kong-Macau Greater Bay Area, universities in Guangdong start to build innovation and entrepreneurship education ecosystems equipped with such functions as education, service, practice and research in order to promote sharing of resources, build a well-functioning ecosystem and bolster regional economic growth. To build innovation and entrepreneurship education ecosystems, universities can make efforts from the following aspects: to perform overall planning in a top-down manner; to improve the global innovation-entrepreneurship course system and promote multi-pronged course reforms; to introduce excellent teachers and build a team of "triple-competent" teachers; to build a platform for improvement of innovation and entrepreneurship education; to improve innovation and entrepreneurship services and provide customized guidance; encourage training of innovators and entrepreneurs with a global vision to support advancement of the Greater Bay Area and the Belt-andRoad Initiative.
\end{abstract}

\section{Introduction}

Since "Innovation and Entrepreneurship for All" rose to a national strategy, China has seen new waves of innovation endeavors and startups, with innovation and entrepreneurship education prevailing across China. Universities, as incubators and the leading force of innovation, cradles for innovators and new entrepreneurs, and institutes where innovation and entrepreneurship education take place, play an important role in economic growth and scientific innovation. China is a late starter in innovation and entrepreneurship education. Universities in Guangdong, within the Guangdong-Hong Kong-Macau Greater Bay Area (hereinafter referred to as the Greater Bay Area), embrace opportunities to develop the bay area into a first-class education highland and a global hub of scientific innovation, but meanwhile face challenges in exchange of innovation elements due to the "one country, two systems" policy and "three tariff zones". Therefore, in-depth studies are necessary to explore how to build innovation and entrepreneurship ecosystems equipped with functions of education, service, research and practice, and analyze how to improve integration of innovation elements in these ecosystems.

\section{Features and elements of innovation and entrepreneurship ecosystems in universities}

Ecosystem is a concept derived from ecology, referring to an integrated system that organisms and their surviving environment create together via interactions in a given region [1]. "Entrepreneurship ecosystem", a concept put forward by MIT, defines how to build an ecosystem to incubate innovators and entrepreneurs. Existing studies in China on innovation and entrepreneurship ecosystems are theoretical studies focused on the features, elements and operational mechanisms of these systems.

\subsection{Features of innovation and entrepreneurship ecosystems in universities}

Entrepreneurship ecosystems are a fruit of crossdisciplinary explorations. The academia has provided different definitions and assigned different features to entrepreneurship ecosystems as the research perspective 
differs. Most studies analyzed the entrepreneurs and the entrepreneurial environment, adopted the systematic thinking of ecology to study the interrelations between elements in the system and explore the influencing mechanism. Some interpreted the entrepreneurship ecosystem from the following aspects: entrepreneurial subjects, entrepreneurial environment, and interactions [1]. Some other studies, an entrepreneurial ecosystem is defined as an organic system that takes the entrepreneurial initiatives as the focus, a system that tracks the development of startups from inception, founding, development to expansion, and a system that consists of supporting individuals, organizations and institutes aiming to create a shared set of values [2].

\subsection{Elements of innovation and entrepreneurship ecosystems in universities}

As a hot research topic, innovation and entrepreneurship ecosystems have been studied from the angles of the social ecosystem and collaborative innovation based on theories of symbiosis, competition and cooperation, coordination, networking and exchange. As the external environment changes, researchers in China and abroad have analyzed the framework, elements, features, operational mechanism and typical cases for innovation and entrepreneurship ecosystems, but the manifestations of the components differ. In light of the classification standards by foreign researchers [3], elements in entrepreneurship ecosystems are divided into two groups: fundamental elements (cultural context, national system, market) and structural elements (labor capital, financial capital and scientific RandD) [1]. The fundamental elements are the foundation to create an environment for these ecosystems, while structural elements are the engine that boosts development of these systems [4]. By using the EPM model, we divide the theoretical research achievements on innovation and entrepreneurship education ecosystems into three dimensions: environment (macro-dimension), platform (meso-dimension) and the driving force (micro-dimension). The "environment" elements are important: a proper environment can ensure smooth operation of the ecosystem, and both national and regional environments have impacts on the construction and optimization of these systems. The "platform" elements involve enterprises and organizations that provide technical support and incubators for entrepreneurship training. The "driving forces" include entrepreneurs, teachers and training courses, and interactions between different driving forces will boost smooth operations of the system [5]. The innovation and entrepreneurship education ecosystem consists of several modules: the subject module, the support module, the carrier module and the environment module. Each module is closely connected and interact with each other: the subject acquires resources from the carrier and support modules, but meanwhile provides a market for the latter two; good interaction among these three modules will improve the environment and in turn boost the subjects' development [6].

\subsection{Operational mechanism of innovation and entrepreneurship ecosystems in universities}

Innovation and entrepreneurship ecosystems in universities consist of the abiotic environment, producers, consumers, decomposers and catalysts [7]. These ecosystems are co-existent, interactive, dynamically balanced and developmental [8]. Connections and interactions between elements in the system gradually evolve into a stable, developmental, open and aggregative ecosystem [6] in an ordered manner. Looked at from the angle of co-evolution theories, an entrepreneurship ecosystem is a loose coupling network in which each element interacts dynamically and evolve with other elements, demonstrating such features as co-existence, autonomy, evolution and the spillover effect. A threecircle structure of the ecosystem has been proposed: the core circle (core subjects directly involved), the inner circle (immediate influencing factors in the environment of universities), and the external circle (indirect factors in the external environment that influence innovation and entrepreneurship training). The elements in the core circle and the inner circle are from inside the universities and thus play a direct and crucial role; those in the external circle influence the ecosystem's overall operations, resource sharing and progress [9]. For intellectual entrepreneurship ecosystems, such as technical innovation and knowledge conversion ecosystems (core), entrepreneur ecosystems (activity subjects), resource ecosystems (social foundation), platforms and policies (supporting frameworks), the heterogeneous resource integration mechanism, cross communication mechanism, technical innovation ability improvement mechanism, and product value realization mechanism are adopted to promote ordered operations of these ecosystems, thus realizing incubation and improvement of entrepreneurial endeavors [10]. In the symbiosis theory and extended logistics model were introduced to build a symbiotic evolution model to demonstrate the evolutionary modes of entrepreneurship ecosystems via digital simulation, revealing the equilibrium of symbiotic evolution of the ecosystem decided by the symbiosis coefficient [11].

\section{Current conditions and problems of innovation and entrepreneurship ecosystems in universities}

Innovation and entrepreneurship education is now in its infancy in Chinese universities. Studies in this regard were focused on the definition, necessity, content and manners of the entrepreneurship education, while few explored how to implement the education. The implementation of innovation and entrepreneurship education in China is monotonous, backward and blind, which undermines the effect of education. Though Chinese universities have made efforts to build a good campus environment and create supportive platforms, such as creating innovation and entrepreneurship incubators, launching contests and 
practice events, few adopt the ecosystem thinking to introduce external resources from the government, enterprises and research institutes. Only with external support can the internal elements and platforms in universities can be improved, and the internal resources including the teachers, courses and incubation bases can be made the best of.

\section{Development ways for innovation and entrepreneurship ecosystems in universities}

In the Greater Bay Area, to build a global education highland and cultivate international innovators and entrepreneurs, universities in Guangdong need to integrate innovation elements inside and outside the region, realize resource sharing, cooperate with each other, and incorporate different functions of universities including research, services, education and practice into the innovation and entrepreneurship education ecosystem. They should also make use of external resources from the government, enterprises, research institutes and other social organizations, and create a university-industryresearch alliance. In this way, universities cannot only provide inspiration for intellectual innovation, but offer talents and technical support for the ecosystem, making all innovation elements highly integrated and improving the ecosystem's effect in talent training, research and social services [12] (Figure 1). 


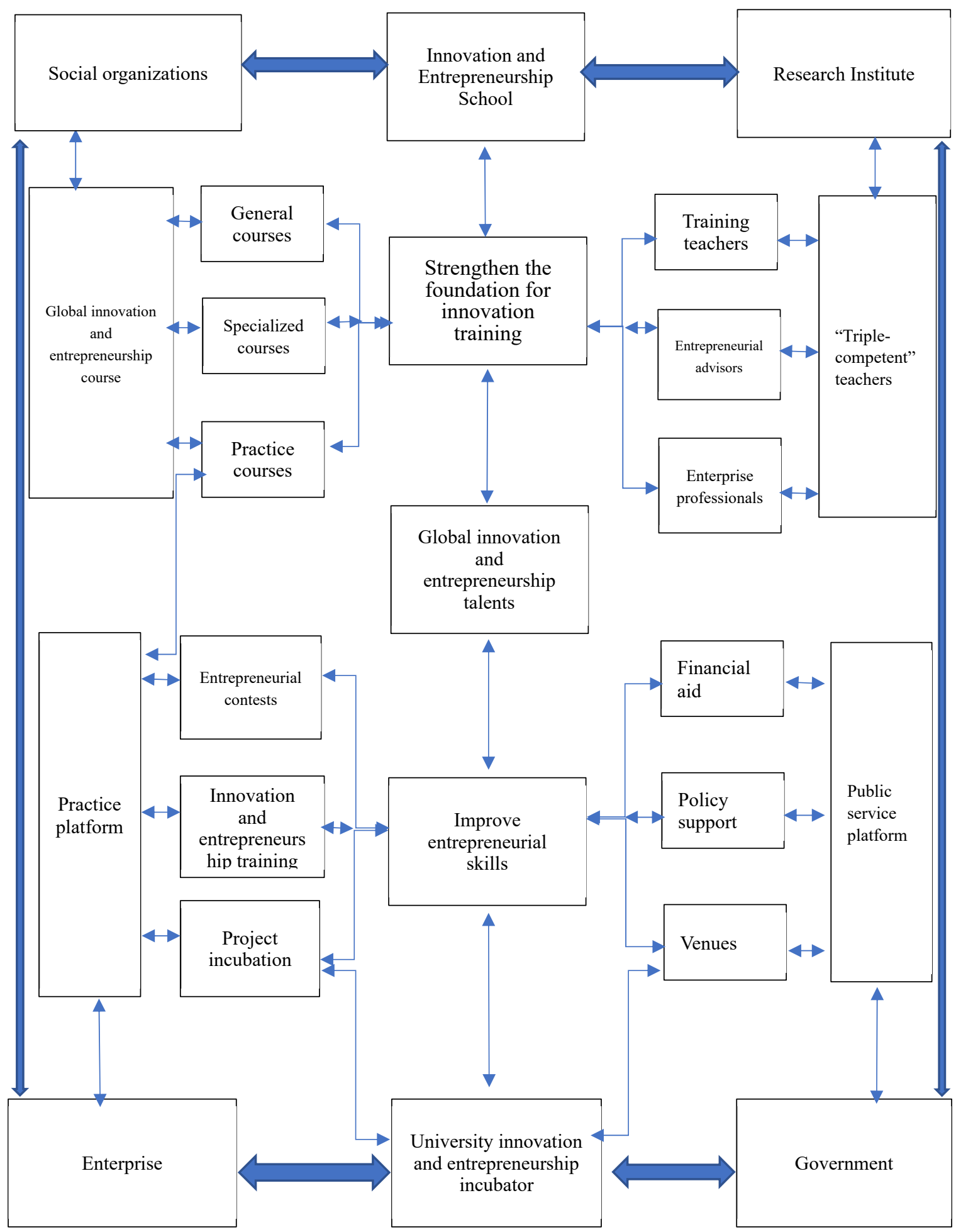

Figure 1. Innovation and entrepreneurship education ecosystem in university

\subsection{Top-down overall planning}

Universities should make a point of and play a leading role in developing the innovation and entrepreneurship ecosystem. Universities should establish a managerial framework with the school president as the person in charge and other departments and secondary teaching units cooperating. An overall plan should be developed to take innovation and entrepreneurship education as the core of talent training and discipline development in universities. To build an innovation and entrepreneurship education ecosystem, universities should juggle four functions - "teaching, practice, research and social services", conduct overall planning, engage external resources from the government, enterprises, research institutes and social service organizations. Among these external resources, the government provides policy support and highquality public services; enterprises provide venues for innovation and entrepreneurship initiatives, facilitate inception of 
startups, and attract more investment to development of the ecosystem; research institutes can provide brainpower for the ecosystem, offer suggestions on planning; social service organizations can provide agency services and offer feedback on the effect of the ecosystem by tracking the implementation of innovation and entrepreneurship education. [13].

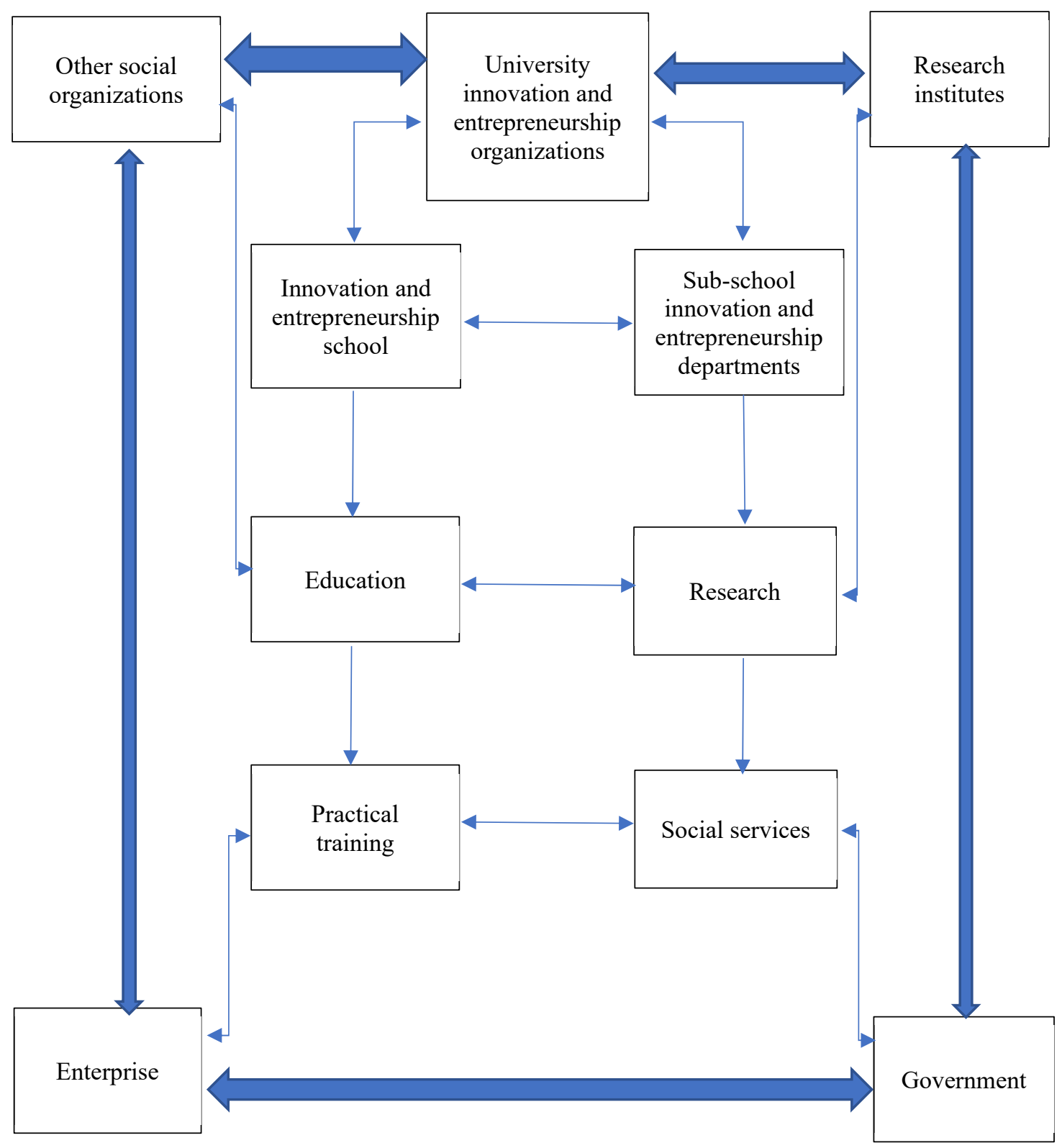

Figure 2: Collaborative mechanism of the innovation and entrepreneurship ecosystem in university

Universities should create an integrated innovation and entrepreneurship education network with partnership with research institutes, encourage sub-schools to join this initiative and ensure overall engagement. Universities should also build a network with the Innovation and Entrepreneurship School as the engine and other subschools as partners, establish a communication mechanism among schools, set up a joint conference system, create an innovation collaboration mechanism in which the students are the core, the Innovation and Entrepreneurship School is the guiding force, and other sub-schools play a collaborative role (Figure 2). Besides, students are the subject of innovation and entrepreneurship training, and in light of the top-down training mode of student societies in the EU, universities in China should make the students as the subject of training, create a top-down framework of "provincial student societies - regional student societies - university student societies - school student societies", allow these student societies to manage daily operations and coordinate exchange of resources at different levels. Moreover, universities can organize innovation and entrepreneurship branding campaigns, create youth entrepreneur exchange platforms, strengthen cooperation between the government, research institutes and enterprises, build a more efficient student innovation and entrepreneurship operation model.

\subsection{Improving the global innovation and entrepreneurship course system and advancing multi-pronged course reforms}


Universities can follow the three-level education model ("general education", "specialized education" and "extended education"), use modernized teaching methods, thus to create a global innovation and entrepreneurship course system. General education on innovation and entrepreneurship should be carried out throughout the talent training process. Universities should learn from western countries in this regard to improve their course systems, design talent training plans and identify training goals. Also, by refining the quality assessment metrics, universities should set the general innovation and entrepreneurship education as a compulsory course to improve the students' all-round skills. Universities can also introduce the STEM training (Science, Technology, Engineering and Mathematics) into the ecosystem, cultivate innovation-minded talents, improve their skills for scientific exploration, and enhance their sense of innovation and problem-solving skills.

Entrepreneurship education should be combined with specialized training. To be specific, universities should use the channels of specialized training, reform the talent training mode, the course content and the course system regarding innovation and entrepreneurship education in specialized training, and create an innovation and entrepreneurship education system. In the meantime, universities can take advantage of modern education platforms, enable resource sharing among different entities and thus create a closely-connected resourcesharing network for innovation and entrepreneurship training. Moreover, innovation and entrepreneurship organizations should incorporate the students' scores in innovation and entrepreneurship courses into the overall scoring system, establish a flexible scoring mechanism, allow students to suspend from school temporarily for entrepreneurial initiatives, provide a score-conversion system and define instructions for conversion. In the meantime, universities should assign academic scores for these entrepreneurship initiatives to encourage students' initiatives for academic innovation and entrepreneurial endeavors.

Universities should promote extended education of innovation and entrepreneurship, and create a "learn-inpractice" model. In innovation and entrepreneurship training programs, universities can invite entrepreneurs to give lectures on policies, venture capitals, entrepreneurial experience to encourage the students' entrepreneurial attempts. They can also make use of advanced courses abroad, both online and offline, to build a global course system, found training camps, enrich the training content and extend the students' global vision.

\subsection{Introducing more teachers to build a faculty of "triple-competent teachers"}

Universities should, following the policy of building a "talent pool of ten thousand innovation and entrepreneurship teachers" proposed by Ministry of Education, introduce "triple-competent teachers", i.e. "theory-competent, practice-competent, all-competent" teachers, establish teacher qualification standards and management regulations to improve the quality of innovation and entrepreneurship education. Universities should make the teachers' efforts in innovation and entrepreneurship training an important basis for teachers' appointment, assessment and title assignment. Also, universities should draw teaching resources from research institutes, think tanks, the government and enterprises, extend the network of innovation and entrepreneurship teachers in a pronged way so as to build a bridge that connects teachers and entrepreneurial projects. Universities can also organize training camps for teachers engaged in innovation and entrepreneurship education, or organize academic conferences in this regard to promote exchange and communication between world-class teaching resources in China and abroad.

\subsection{Setting up platforms for innovation and entrepreneurship education}

Efforts should be made to unite universities, the government, industries and enterprises in innovation and entrepreneurship education. Universities should organize field trips to enterprises to help students learn more about polices and environments for entrepreneurial initiatives and take a closer look at startups. Universities can also cooperate with each other to hold regional, national or global contests on innovation and entrepreneurship, organize influential contests to provide students easier access to social resources. To build entrepreneurship practice platforms, universities can work together across regions, create entrepreneurial groups via bidding, and make use of resources from different channels to build a locally-characteristic repository of entrepreneurs.

Universities can create innovation and entrepreneurship bases in cooperation with the government, enterprises and research institutes, make innovation on the entrepreneurial practice sites, encourage intellectual innovation and speed up conversion from innovation to scientific achievements. Universities can also set up functional departments to standardize innovation and entrepreneurship programs, build an innovation and entrepreneurship chain consisting of school innovation workshops, innovation and entrepreneurship incubators, school-enterprise collaborative platforms, and scientific enterprise incubators. They can draw experience from "Advancing CUHK Entrepreneurship Hub" in Hong Kong to divide student entrepreneurship programs into different stages, i.e., the inception stage, initial stage and expansion stage, providing all-round innovation and entrepreneurship education [14]. Universities should build a network of resources for innovation and entrepreneurship education to realize "pre-incubation" (innovation and entrepreneurship workshops mining projects), "initial incubation" (innovation and entrepreneurship incubators selecting projects), and "in-depth incubation" (regional support for innovation platforms and conversion projects) [15].

\subsection{Improving the innovation and entrepreneurship service system to provide customized service}


Universities should make use of external resources from the government, enterprises and other organizations, establish one-stop service platforms for innovators and entrepreneurs, improve technology transfer systems, and provide quality public services. The services should cover interpretation of policies, free legal consultation, resource connection platforms, entrepreneurial experience sharing, and project matching as well as financial support. The objective is to allow students benefit from the policies and increase the success rate of connection of innovation and entrepreneurship projects with the market. In-campus startup incubators should provide guidance before entrepreneurial initiatives and invite experts to provide suggestions. Students with an entrepreneurial mind can select services according to the experts' suggestions to solve problems in their entrepreneurial endeavors. Also, by taking advantage of campus media, universities can set examples, provide guidance, and deliver messages on policies to create a good favorable environment for innovation and entrepreneurship initiatives. In addition, they can raise fund from diverse channels to ensure financial support and create an entrepreneur incubation foundation through school financial aid, alumni donation and enterprise investment. They can also organize innovation and entrepreneurship contests, practice activities and venture capital events to support students' entrepreneurial endeavors so that capital assets can be invested into scientific industries more efficiently and flexibly [16].

\section{About the Author}

Qianyu Zhu (1986- ), Female, Lecturer and Ph.D. candidate of Guangdong University of Foreign Studies, with research interests covering innovation and entrepreneurship education, ideological and political education for college students, etc.

\section{References:}

1. Sun Jinyun, Li Tao. Entrepreneurial ecosystem: from the perspective of symbiotic evolution and organizational ecology theories $[\mathrm{J}]$. Foreign Economics \& Management. 2016, 38(12): 32-45.

2. Chen Lingmin, Wang Xiaoxiao, Mao Ruixin. Modelling and operational mechanism of entrepreneurial ecosystem [J]. Ecological Economy, 2019, 35(09): 55-60;

3. Nir Kshetri. Developing successful entrepreneurial ecosystems: Lessons from a comparison of an Asian tiger and a Baltic tiger. Baltic Journal of Management, 2014, 9(3):330 - 356.

4. Erik Stam. Entrepreneurial Ecosystems and Regional Policy: A Sympathetic Critique. Working Papers, 2015, 23(9)

5. Chang Jin, Chen Fengwen. Development of entrepreneurial training ecosystems in universities using the EPM model [J]. Higher Education Exploration, 2019 (11): 118-123.

6. Chang Tingting \& Wang Qiushi. Research on operational mechanism of entrepreneurial ecosystems [J]. Information and Communications Technology and Policy, 2019 (3): 7-9.

7. Tao Qiuxiang, Tu Jiliang, Du Wei. Construction of innovation and entrepreneurship training ecosystems and regional development from the dimension of "double first-rate school development" [J]. Journal of Nanchang Hangkong University (Social Science edition), 2019, 21(03): 110-118.

8. Du Dong, Hong Jingyue. Panoramic analysis and comprehensive assessment of innovation and entrepreneurship ecosystems in universities [J]. Shangdong Higher Education, 2019, 7 (1): 17-26.

9. $\mathrm{Xu}$ Weili, Ge Xinwei. Research on channels to develop innovation and entrepreneurship ecosystems in vocational schools [J]. The Chinese Society For Technical And Vocational Education, 2020, (01): 8386.

10. Li Yanyan, Huang Zhaoxin. Development and operational mechanism of intellectual entrepreneurship ecosystems [J]. Research in Higher Education of Engineering, 2017, (06):168-172.

11. Li Hongbo, Shi Huan. Research on symbiotic evolution of entrepreneurial ecosystems using the extended logistic model [J]. Statistics \& Decision, 2019,35(21):40-45.

12. Li Jing, Liu Hui. Logic and direction of higher education integration in the Guangdong-Hong KongMacau Greater Bay Area [J]. Research on Higher Education, 2018,39(10):31-36.

13. Wang Zhenzhen, Li Qingqing, Bao Xinghua. Responsibilities and collaborative development of the government, universities, enterprises and the society in innovation and entrepreneurship training ecosystems - a comparative study between the US, Germany and Japan [J]. Forum on Science and Technology in China, 2019, (09):182-188.

14. Wang Zhanren, Ou Yuhui. Practice and Inspiration in innovation and entrepreneurship training system development from Hong Kong - A case study of Advancing CUHK Entrepreneurship Hub [J]. Innovation and Entrepreneurship Education, 2017, 8(01):20-23.

15. Zhang Chao, Zhang Yuguang. Research on operational strategies of innovation and entrepreneurship training systems in universities from the angle of ecological niche [J]. Research and Exploration in Laboratory, 2019,38(01):163-166.

16. Yang Debin. Important factors of scientific entrepreneurship ecosystems - scientific development potential of Hong Kong and cooperation with four regions in mainland China $[\mathrm{J}]$. Science \& Technology Industry of China, 2014, (06):25-27. 